
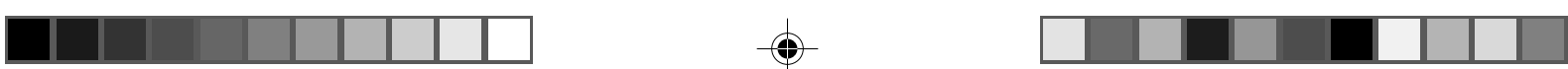

\title{
Tráfico internacional de mulheres na Amazônia: desafios e perspectivas"
}

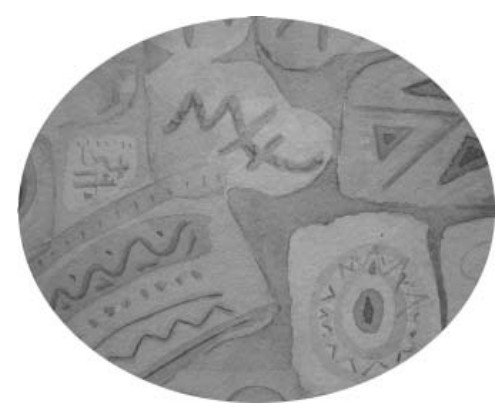

Márcia Maria de Oliveira **

\section{Resumo}

$\mathrm{Na}$ perspectiva da sociodiversidade, são abordadas as relações sociais e existenciais dos diversos grupos humanos com seus padrões próprios de organização social, sua autonomia no exercício político, que determina padrões específicos de identidades socioculturais de acesso ou pertencimento territorial. Isso implica em uma existência humana relacional em constante dinâmica, como o que ocorre na Amazônia com os mais variados povos em suas singularidades.

Palavras-chave: Estudos de gênero. Amazônia. Tráfico de mulheres.

\section{Abstract}

The social and the existential relations of the diverse human groups with their own patterns of social organization, their autonomy in the political exercise, which determines specific patterns of socio-cultural identities of access or territorial belonging have been approached within a sociodiversity perspective. This implies a constant dynamic relational human existence with what occurs in the Amazon region with the most diverse people in their uniqueness.

\footnotetext{
"Artigo apresentado no Grupo de Trabalho: Migrações, Violência e Tráfico de Mulheres na Amazônia. GT do I Emflor - Encontro de Estudos das Mulheres da Floresta realizado na Universidade Federal do Amazonas de $19-21$ e outubro de 2009.

* Socióloga, Mestre em Sociedade e Cultura, Doutoranda do Programa de Pós-Graduação em Sociedade e Cultura na Amazônia (PPGSCA/Ufam); Pesquisadora do Grupo de Pesquisas sobre Migrações na Amazônia (Gema) e pesquisadora do Grupo de Pesquisas e Observatório Social - GEPOS/Ufam, Pesquisadora do Observe: Observatório da Lei Maria da Penha.
} 
Keywords: Gender studies. Amazônia. Trafficking of women.

\section{Introdução}

Pensar a Amazônia sob a perspectiva dos estudos de gênero é um grande desafio para as ciências humanas. Esta abordagem só é possível a partir da compreensão da Amazônia em sua sociodiversidade.

Na perspectiva da sociodiversidade, são abordadas as relações sociais e existenciais dos diversos grupos humanos com seus padrões próprios de organização social, sua autonomia no exercício político, que determina padrões específicos de identidades socioculturais de acesso ou pertencimento territorial. Isso implica em uma existência humana relacional em constante dinâmica, como o que ocorre na Amazônia com os mais variados povos em suas singularidades.

Ao percorrer os estudos da sociodiversidade na Amazônia, se percebe outro grande desafio que é a compreensão da mulher e seu papel nesta região. Nesta perspectiva, as relações de gênero são uma chave de leitura importante para se compreender a sociodiversidade e seus desafios na Amazônia (TORRES, 2005). Neste contexto de sociodiversidade, para se compreender a "mulher amazônida" é necessário considerar inúmeros fatores de ordem cultural, política e econômica a partir da complexidade que é a Amazônia.

A proposta deste breve artigo é justamente apresentar algumas pistas para a reflexão sobre a condição da mulher na Amazônia, adentrando à problemática do tráfico de mulheres para fins de exploração sexual comercial na região. Trata-se de uma temática complexa e pouco debatida, mas de grande relevância para os estudos de gênero nesta região.

\section{Breves reflexões sobre a condição da mulher na Amazônia e o tráfico inter- nacional de pessoas para fins de exploração sexual comercial}

Se a compreensão da sociodiversidade na Amazônia já se apresenta como algo um tanto complexo e difícil de ser entendido, a compreensão da condição da mulher na Amazônia é ainda mais complexa. Os estudos de Torres (2005) indicam que os estudos das relações de gênero na Amazônia ainda permanecem pouco

74 Somanlu, ano 9, n. 1, jan./jun. 2009 
explorados pelos pesquisadores da região. Ainda são poucas as pesquisas sobre o perfil da mulher e seus impactos na sociodiversidade definindo quem são essas "amazônidas" e qual a relevância de seu papel nesta sociedade marcada pela pluriculturalidade.

Uma análise sociológica sobre esta temática passa, necessariamente, pela análise histórica desta região marcada pelas relações de exploração e pela prática permanente do tráfico humano. Tal prática é identificada desde a intervenção arbitrária dos colonizadores que transformaram os homens-livres da floresta em escravos nas descimentas ${ }^{1}$ tornando as mulheres vulneráveis à exploração sexual.

A partir da segunda metade do sec. XIX, com a exploração do látex, mais de 300.000 (trezentos mil) trabalhadores foram trazidos ${ }^{2}$ do Nordeste para a Amazônia (LOUREIRO, 1982) nos moldes do tráfico humano, que implicava no aliciamento e recrutamento dos ditos "soldados da borracha". Outro fator que caracterizava a situação de tráfico era o confinamento dos trabalhadores no interior dos seringais e o seu endividamento premente que implicava no pagamento das taxas de viagem e na aquisição de instrumentos de trabalho, de alimentos e materiais de primeira necessidade tais como remédios, roupas, utensílios domésticos e artigos de higiene pessoal.

No mesmo processo em que ocorria o tráfico de homens, o recrutamento de mulheres passou a ser praticado em larga escala pelos agenciadores da economia gomífera que as traziam, principalmente do nordeste, para fins de prostituição com o objetivo de atenuar a tensão no interior dos seringais e dos barracões, de onde se controlava a extração do látex e o escoamento da borracha para os centros de comercialização ${ }^{3}$. Além disso, muitas mulheres indígenas eram arbitrariamente "capturadas" pelos seringueiros nos arredores das aldeias (PANTOJA, 2006, p. 79).

Ao tentar compreender os aspectos históricos que tornam as mulheres da Amazônia vulneráveis à prostituição e ao tráfico humano, $\mathrm{Hazeu}^{4}$, conclui que:

Na Amazônia, a mulher sempre foi percebida em segundo plano. Os programas de desenvolvimento, os investimentos, as políticas socioeconômicas sempre foram direcionados para o agronegócio e mineração, que procuram trabalhadores masculinos. A presença da mulher e as questões da sua sobrevivência foram consideradas uma consequência do trabalho masculino. Nesta lógica, as mulheres migraram para

Somanlu, ano 9, n. 1, jan./jun. 200975 
dentro da Amazônia atrás dos homens pioneiros, seringueiros, garimpeiros, trabalhadores de construção, marinheiros e caminhoneiros para ocupar os serviços por eles desejados: trabalhadoras domésticas, prostitutas e/ou para um eventual casamento, muitas vezes através de aliciadores e traficantes. Este dinamismo fragilizou a posição da mulher na Amazônia e produziu uma cultura permissiva à exploração sexual (HAZEU, 2006, p. 5).

Os elementos apresentados por Hazeu representam um recorte histórico importante onde as mulheres foram fragilizadas na sua condição feminina na Amazônia. Isso é fato. Também é fato que na sequência do Ciclo da Borracha, as mulheres continuaram sendo traficadas na Amazônia para fins de exploração sexual nos garimpos e nas casas noturnas de Manaus no apogeu da Zona Franca.

Mas, há outros elementos de ordem política, econômica, social e cultural que condicionam muitas mulheres ao tráfico internacional na Amazônia. Nesse sentido, um fator de grande relevância é o estereótipo que as mulheres da Amazônia carregam na relação com outros Estados e regiões do Brasil e com outros países: a de "mulher exótica" de "sexo forte e selvagem" que, trocando em miúdos, significa diferente e excêntrica. Na verdade este estereótipo nada mais é do que a justificativa para a legitimação da sevícia e da exploração da condição feminina vendida pelos marqueteiros do "turismo" sexual aos estrangeiros que vêm "visitar" a Amazônia.

Uma dimensão importante neste contexto indica que boa parte do chamado "turismo ecológico", que na verdade é uma justificativa para o turismo sexual, é financiado pelo próprio Estado. Só para se ter uma ideia, as maiores festas "temáticas" da Amazônia, onde ocorre a maior parte dos aliciamentos de mulheres e meninas, são totalmente financiadas pelo governo estadual juntamente com as grandes empresas patrocinadoras dos eventos ${ }^{5}$. Nessas ocasiões, tanto ocorre exploração sexual com a prostituição de mulheres e meninas nos locais das festas, quanto também, ocorre o aliciamento para o tráfico internacional dissimulados por propostas de trabalho, de melhores condições de vida e, o mais absurdo de todos, casamento rápido consequência de "amor à primeira vista".

Muitas meninas e mulheres que embarcam no retorno dos turistas das grandes festas, nunca mais retornam aos seus familiares. Diferentemente dos migrantes

76 Somanlu, ano 9, n. 1, jan./jun. 2009 


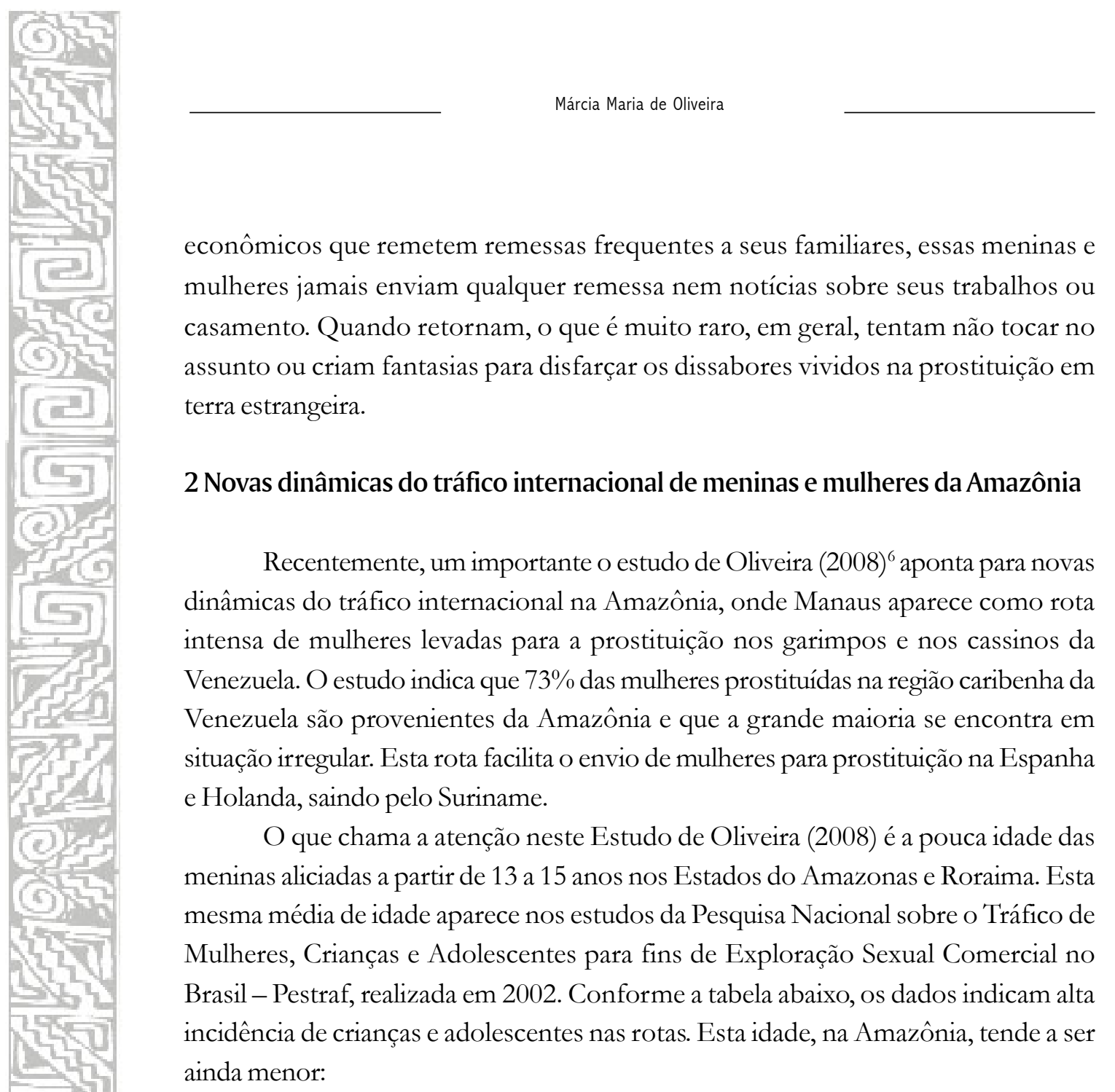

econômicos que remetem remessas frequentes a seus familiares, essas meninas e mulheres jamais enviam qualquer remessa nem notícias sobre seus trabalhos ou casamento. Quando retornam, o que é muito raro, em geral, tentam não tocar no assunto ou criam fantasias para disfarçar os dissabores vividos na prostituição em terra estrangeira.

\section{Novas dinâmicas do tráfico internacional de meninas e mulheres da Amazônia}

Recentemente, um importante o estudo de Oliveira $(2008)^{6}$ aponta para novas dinâmicas do tráfico internacional na Amazônia, onde Manaus aparece como rota intensa de mulheres levadas para a prostituição nos garimpos e nos cassinos da Venezuela. O estudo indica que $73 \%$ das mulheres prostituídas na região caribenha da Venezuela são provenientes da Amazônia e que a grande maioria se encontra em situação irregular. Esta rota facilita o envio de mulheres para prostituição na Espanha

O que chama a atenção neste Estudo de Oliveira (2008) é a pouca idade das meninas aliciadas a partir de 13 a 15 anos nos Estados do Amazonas e Roraima. Esta mesma média de idade aparece nos estudos da Pesquisa Nacional sobre o Tráfico de Mulheres, Crianças e Adolescentes para fins de Exploração Sexual Comercial no Brasil - Pestraf, realizada em 2002. Conforme a tabela abaixo, os dados indicam alta ainda menor:

Tabela 1 - Média de idade das pessoas traficadas.

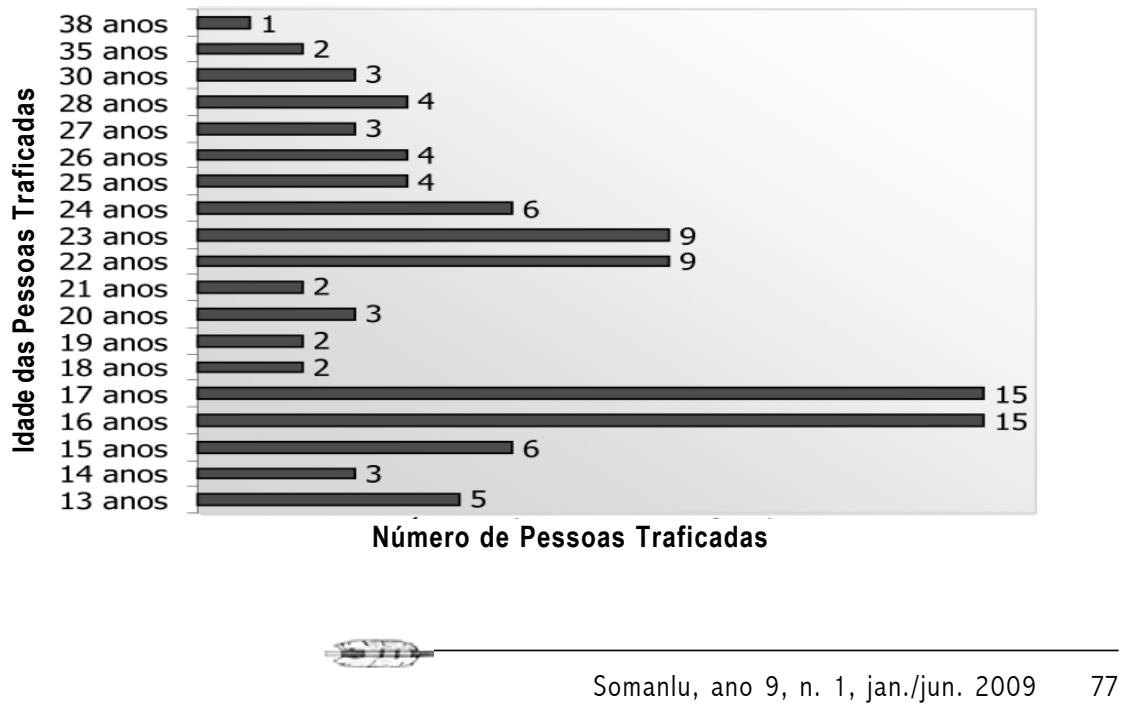


O Centro de Referência, Estudos e ações sobre Crianças e Adolescentes Cecria - vem atualizando os dados apresentados pela Pestraf refazendo os estudos e o mapeamento das rotas. $\mathrm{Na}$ realidade amazônica, os estudos indicam que as rotas do tráfico permanecem em grande atividade e que as redes do tráfico estão cada vez mais fortalecidas na região.

Tabela 2 - Geografia das rotas segundo a Pestraf.

\begin{tabular}{|l|c|c|c|c|}
\hline Região de Origem & Internacional & Interestadual & Intermunicipal & Total \\
\hline Sul & 15 & 9 & 4 & 28 \\
\hline Sudeste & 28 & 5 & 2 & 35 \\
\hline Centro-Oeste & 22 & 8 & 3 & 33 \\
\hline Nordeste & 35 & 20 & 14 & 69 \\
\hline Norte & 31 & 36 & 9 & 76 \\
\hline Total & $\mathbf{1 3 1}$ & $\mathbf{7 8}$ & $\mathbf{3 2}$ & $\mathbf{2 4 1}$ \\
\hline
\end{tabular}

Fontes: Pestraf/Banco de Matérias Jornalísticas/2002;

Relatório Nacional Pestraf/2002 (rotas). IBGE, 1999/2000.

O tráfico internacional de seres humanos, há séculos, vem marcando a história da humanidade como um estigma difícil de ser extirpado. Trata-se de um dilema que envolve pessoas de todas as partes do mundo. Atualmente, figura entre os crimes internacionais com maior lucratividade, só perdendo para o tráfico internacional de drogas e de armas ${ }^{7}$.

Tabela 3 - Rotas dos países de destino do tráfico.

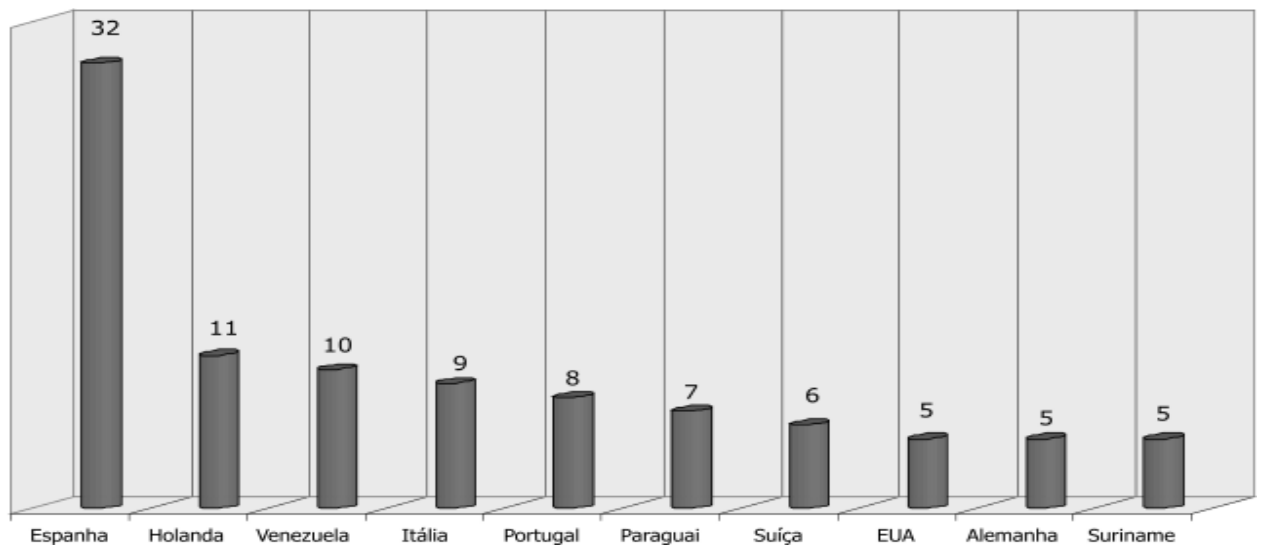

Fonte: Pestraf - Banco de Matérias Jornalísticas /2002

78 Somanlu, ano 9, n. 1, jan./jun. 2009 


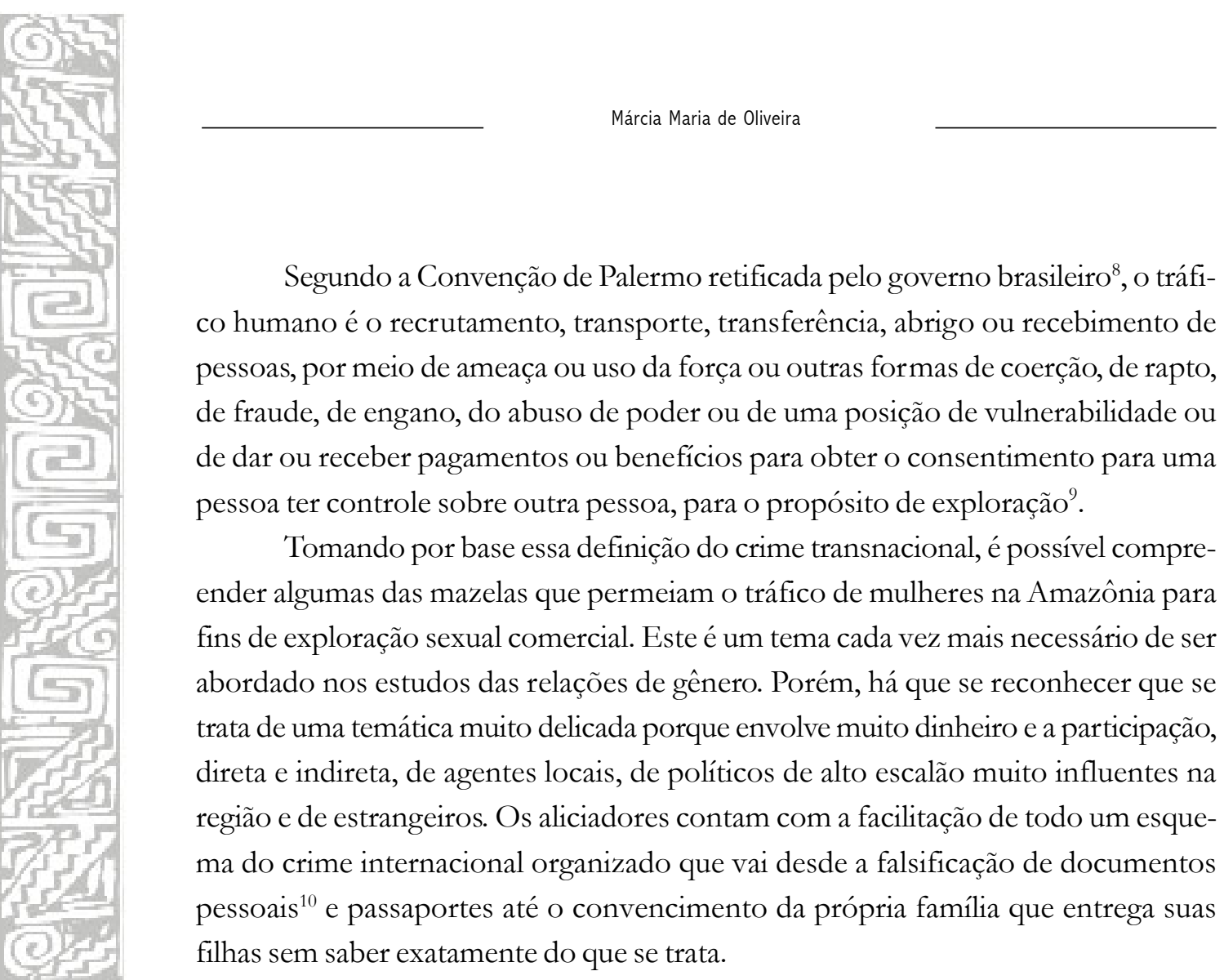

\section{Algumas pistas sobre a rota do tráfico em Manaus}

Um grande limite nestes estudos é justamente o acesso às vítimas que preferem ficar no anonimato por não conseguirem o apoio necessário, nem no país estrangeiro, nem no Brasil, para superar os traumas e dissabores desta odisseia. Por isso, boa parte dos estudos resulta das análises e denúncias das instituições que atuam no combate ao tráfico internacional.

Recentemente, um breve estudo realizado com os alunos da disciplina de Sociologia do primeiro período do Curso de Geografia da Universidade Federal do Amazonas trouxe à tona novos detalhes das rotas do tráfico na Amazônia a partir da realidade de Manaus. O Estudo, intitulado: "Cartografia da Prostituição em Manaus"11, identificou várias mulheres em situação de prostituição que foram vítimas recentes do tráfico internacional. Os depoimentos recolhidos ao longo da pesquisa indicam as redes de favorecimento do tráfico muito parecidas com aquelas já apontadas pela Pestraf que são: 
- Rede de entretenimento (shoppings centers, boates, bares, restaurantes, motéis, barracas de praia, lanchonetes, danceterias, casas de shows, quadras de escolas de samba, prostíbulos, casas de massagens);

- Rede do mercado da moda (fashion): agências de modelos (fotográficos, vídeos, filmes);

- Rede de Agências de Emprego: empregadas domésticas, baby-sitters, acompanhantes de viagens e trabalho artísticos (dançarinas, cantoras, go go girls);

- Rede de Agências de Casamento;

- Rede de telessexo: anúncios de jornais, internet e TVs (circuito interno).

- Rede da Indústria do Turismo - agências de viagem, hotéis, spas/resorts, taxistas, transporte do turista;

- Redes de Agenciamento para Projetos de desenvolvimento e infraestrutura, recrutamento para frentes de assentamentos agrícolas, construção de rodovias, hidrovias, mineração (garimpos) e outros.

Em Manaus, foram identificadas muitas rotas intermediadas pelos famosos "hotéis de selva" e pelas festas temáticas. O grande projeto de "turismo ecológico", amplamente divulgado e financiado pelo atual governo do Estado continua sendo estratégia para o "turismo sexual" facilitando as rotas para o tráfico das meninas aliciadas. Há situações de aliciamento em comunidades indígenas e ribeirinhas, especialmente aquelas que se localizam nas proximidades de garimpos ou de fronteiras internacionais: Colômbia, Peru, Guiana Francesa e Venezuela.

Durante a realização da pesquisa foram entrevistadas várias mulheres e meninas que escaparam ao tráfico mediante informação e esclarecimento antes do embarque. As vítimas do tráfico que retornaram a Manaus, no geral, apresentam histórico de intensa violência sexual. A título de exemplificação, escolhemos um depoimento de uma vítima que, por certo, consegue resumir a tragédia do tráfico de mulheres da Amazônia:

Eu fui de Manaus (Bairro Conquista), junto com várias amigas, para a Festa de Parintins no dia 24 de junho de 2000. $\mathrm{Na}$ época, tinha 14 anos. Ainda no barco, conheci um 'gringo' muito simpático que estava junto com outros colegas da Holanda. Naquela noite ele tentou dormir comigo na minha rede dizendo que estava muito encantado com minha beleza e que nunca tinha visto uma mulher tão atraente e sensual. Não dormi com ele porque tinha muita gente. Quando che-

80 Somanlu, ano 9, n. 1, jan./jun. 2009 

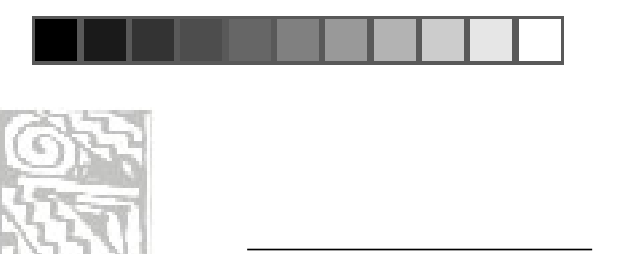

Márcia Maria de Oliveira

gamos em Parintins, percebi que ele tinha muitos contatos com outros 'gringos' de vários outros países, mas, nem desconfiei do que se tratava. Durante o festival, ele me apresentou a vários amigos que me ofereciam sempre muito dinheiro para transar com eles. Faturei uns oitocentos reais durante a festa. No último dia, o dito rapaz chegou pra mim e perguntou se não queria viajar com ele, conhecer a Holanda, depois ir visitar os amigos na Itália, em Portugal e em quantos países eu quisesse. Fiquei balançada com a proposta. Ele disse que podia confiar que ele me pagava a passagem. Falei que não tinha passaporte. Ele pediu meus documentos. Eu só tinha levado minha carteirinha de vale estudantil. Entreguei para ele de manhã. Quando foi lá pelas quatro da tarde, ele apareceu com todos os documentos (identidade e passaporte) que afirmavam que eu tinha 19 anos e com a passagem de ida para Holanda. Fiquei tão feliz. Quando fui contar para minhas amigas, descobri que ele tinha feito a mesma proposta para várias delas e, quando embarcamos no aeroporto de Manaus, sem avisar a nossas famílias, éramos quatro garotas, todas menores de idade como eu. Mal chegamos e já começou tudo: seguraram nossos documentos, deram-nos roupas e tabelas com preços e horários para programas com vários homens naquela primeira noite. Daí por diante, foi só sofrimento. Logo perdi o contato com minhas amigas. A cada ano chegavam novas 'remessas', como diziam, do festival. Em 2007, depois de sofrer todo tipo de violência e humilhação que se pode imaginar, consegui sair da boate, porque, no final, já estavam me descartando das tabelas porque eu já estava muito 'frouxa' e os clientes já não me queriam mais. Como não tinha grana para voltar, procurei fazer uns bicos por fora, trabalhava de babá durante o dia e fazia alguns programas durante as noites. Trabalhei muito até conseguir a grana da volta e juntar algum para não chegar de mão abanando. No final de 2008 consegui retornar para Manaus. Minha família havia se mudado e foi difícil reencontrá-los. Depois, descobri que lhes haviam informado que eu havia morrido no rio Amazonas. Foi uma grande surpresa para todos, mas, eu nunca tive coragem de contar para eles o que aconteceu comigo nesses tantos anos. Inventei uma história que havia sido sequestrada por engano e que depois consegui escapar. Eles nem sonham com o que realmente aconteceu e eu rezo todos os dias para eles nunca

Somanlu, ano 9, n. 1, jan./jun. 2009 
saberem. Soube que uma das minhas amigas daqui de Manaus que estava lá, doou um rim e morreu por causa disso. $\mathrm{Na}$ verdade, acho que arrancaram os rins dela porque vi fazerem isso com várias mulheres que já não "serviam" mais para a prostituição. Hoje, tudo que peço a Deus é que as garotas não caiam nessa fria que eu caí. Nunca mais hei de voltar a esse Festival de Parintins (PESQUISA DE CAMPO, 2009).

À pedido da própria vítima, esse depoimento foi liberado para publicação para ser utilizado como forma de esclarecimento e alerta para as vítimas em potencial.

As poucas vítimas que conseguem retornar dos países estrangeiros denunciam que sofreram todo tipo de abuso e violência. Essas denúncias, que não são muito frequentes, têm sido amplamente divulgadas pela mídia independente e pelas instituições nacionais e internacionais que trabalham no combate ao tráfico. Porém, os esforços não têm conseguido diminuir o fluxo do tráfico na Amazônia:

Inicialmente as mulheres que ingressam em países de forma ilegal, ou ultrapassam o período estipulado em seus vistos, são particularmente vulneráveis à exploração. $O$ padrão é similar em muitos países: mulheres jovens que procuram trabalhos legítimos são ludibriadas por agentes especializados em tráfico de pessoas. Ao chegarem em um país estranho, seus documentos são 'confiscados' e seus movimentos são restritos. Mesmo que elas tenham oportunidade, não procuram ajuda por receio de represálias, de serem tratadas como criminosas ou da repatriação. As mulheres são estupradas, agredidas e drogadas pelos seus exploradores [...] Enquanto as mulheres não gozarem de oportunidades iguais na educação, moradia, alimentação, emprego, enquanto não tiverem alívio do trabalho doméstico não-remunerado, enquanto seu acesso ao poder do Estado e à liberdade não for garantido, vão continuar na lista das vítimas preferenciais da violência e do tráfico (CMI BRASIL, 2005) ${ }^{12}$.

Muitos elementos poderiam ainda ser aprofundados a partir dos depoimentos das vítimas e das instituições. Essas são apenas algumas considerações que podem contribuir para uma análise mais aprofundada desta temática na Amazônia a partir das provocações dos estudos das relações de gênero.

82 Somanlu, ano 9, n. 1, jan./jun. 2009 


\section{Conclusão}

Estas breves reflexões resultam de estudos preliminares que apontam para futuros aprofundamentos. Este estudo identifica que a questão do tráfico humano na Amazônia implica principalmente as mulheres e as meninas pouco informadas sobre os riscos da prostituição e da exploração sexual em países estrangeiros.

Percebemos que a Amazônia continua apresentando o maior número de rotas de tráfico. O Relatório da Região Norte da pesquisa Pestraf cita as características geográficas e culturais da Amazônia como fatores que favorecem o processo de tráfico de seres humanos. A história da região e os planos para seu desenvolvimento, através de fronteiras extensas, com sete países vizinhos também contribuem para facilitar o tráfico.

O isolamento geográfico e a precária infraestrutura de controle das fronteiras, sem fiscalização, e a permanente dinâmica migratória na região, são elementos que tornam a Amazônia vulnerável ao tráfico de mulheres para fins de exploração sexual comercial.

É importante ver que na Amazônia ocorre o tráfico interno e internacional (Guiana Francesa, Venezuela, Bolívia e Suriname) e o transcontinental (países mais apontados: Holanda, Alemanha e Espanha) ${ }^{13}$.

Uma característica particular do tráfico de mulheres na Amazônia é a existência de minas de ouros e projetos de desenvolvimento, áreas onde têm muitos homens trabalhando longe das famílias, o que provoca tráfico com o fim de prostituição.

A falta de políticas públicas para mulheres é um dos principais motivos para a vulnerabilidade das mulheres da Amazônia ao tráfico internacional.

Em todas as análises, emerge a necessidade de subsidiar as instituições responsáveis para o enfrentamento ao tráfico de mulheres e crianças para fins de exploração sexual comercial na Amazônia. Cabe às instituições manter uma dinâmica permanente de orientação e informação por meio de campanhas e de debates, de elaboração de material impresso para informar e advertir as vítimas em potencial. Da mesma forma, é preciso criar mecanismos de encorajamento à denúncia de possíveis mecanismos de aliciamento e suspeitas da atuação das redes do tráfico. Ou seja, a prevenção continua sendo uma estratégia importante e incisiva no enfrentamento ao tráfico. Segundo este breve estudo, é preciso manter a sociedade em alerta permanente. 
Este estudo também aponta para a necessidade de se investir mais nas pesquisas sobre esta temática e sobre as relações de gênero na Amazônia a fim de aprofundar mais sobre a vulnerabilidade da região ao tráfico humano e identificar os mecanismos que promovam rupturas para com este histórico de vulnerabilidade legado às mulheres na Amazônia.

\section{Notas}

1. Expressão utilizada para indicar o envio de índios feitos escravos da Amazônia para o Nordeste do Brasil no Sec. XVII. As descimentas eram parte das políticas coloniais de resgates, entradas, descimentas e aldeamento praticadas com os índios da Amazônia.

2. O verbo "trazer" indica que os soldados da borracha não vieram para a Amazônia por sua livre vontade, mas, foram recrutados pelos agentes oficiais do Estado para o trabalho nos seringais. Isso implica que não houve um "projeto migratório" e sim um deslocamento compulsório de milhares de pessoas do Nordeste para a Amazônia. 3. A borracha era extraída das seringueiras nativas, espalhadas no interior da floresta que havia sido repartida em grandes "quadras" ou fazendas. Os seringalistas, donos das terras de seringais, cobravam uma taxa dos seringueiros para a extração do látex e controlavam a venda do produto que era trazido "in natura"em forma de porungas até os "barracões" aonde os coronéis da borracha as compravam, pagando, por quilo, sempre um preço pré-determinado. Os seringueiros recebiam seu pagamento já descontado todos os gastos superfaturados pelos coronéis. Não raro, estas negociações eram carregadas de tensões e conflitos que resultavam em mortes e todo o tipo de violência e violação de direitos.

4. Esse texto pode ser conferido em: www.faor.org.br/CD/download/ 4_trafico_seres_humanos.pdf.

5. Por exemplo, o Festival dos Bumbás de Parintins no mês de junho e a Festa do Peixe ornamental de Barcelos, mês de agosto são duas festas que recebem grande número de turistas estrangeiros e de outras regiões do Brasil.

6. O texto "Um olhar sobre as redes de prostituição e tráfico de mulheres na fronteira Brasil-Venezuela a partir das rodovias BR-174 e Troncal 10" foi apresentado no X Coloquio Internacional de Geocrítica: Diez Años de cambios en el Mundo, en la

84 Somanlu, ano 9, n. 1, jan./jun. 2009 
Geografía y en las Ciencias Sociales, 1999-2008 - Barcelona, 26 - 30 de mayo de 2008 - Universidad de Barcelona.

7. Segundo levantamento do Escritório das Nações Unidas Contra Drogas e Crime (Unodc), o tráfico internacional de mulheres e crianças movimenta, anualmente, de US\$ 7 bilhões a US $\$ 9$ bilhões, perdendo em lucratividade apenas para o tráfico de drogas e o contrabando de armas. Estima-se que, para cada ser humano transportado ilegalmente de um país para outro, o lucro das redes criminosas chegue a US\$ 30 mil. Maiores informações no: http://www.justica.sp.gov.br/ Modulo.asp?Modulo $=460 \&$ Cod $=2$.

8. A Convenção de Palermo é o nome pelo qual é mais conhecida a Convenção das Nações Unidas contra o Crime Organizado Transnacional. Foi adotada em Assembleia da Organização das Nações Unidas (ONU), no mês de novembro do ano de 2000, na cidade de Nova Iorque. No Brasil, a Convenção de Palermo só foi promulgada quatro anos depois, com a edição do Decreto 5.015, de março de 2004.

9. Protocolo para Prevenir, Suprimir e Punir o Tráfico de Pessoas, Especialmente Mulheres e Crianças, em suplemento à Convenção das Nações Unidas contra o Crime Organizado Transnacional.

10. No caso das menores (que são em grande quantidade) que têm sua idade alterada na carteira de identidade.

11. Esta pesquisa, por mim coordenada na condição de professora da disciplina de Sociologia, envolveu todos os 60 alunos da turma que foram divididos em grupos temáticos que pesquisaram os principais redutos da prostituição na cidade de Manaus com a finalidade de elaborar uma cartografia da realidade. A pesquisa foi realizada no primeiro período de 2009 e apresentada como critério de avaliação da disciplina. O que era para ser apenas um exercício cartográfico terminou apontando elementos importantes sobre as rotas do tráfico de mulheres em Manaus.

12. Cimi-Centro Mídia Independente:WWW.midiaindependente.org. Artigo disponível em http://www.midiaindependente.org/pt/blue/2005/05/316578.shtml 13. A Espanha ainda não ratificou o Convênio Europeu contra o Tráfico de Seres Humanos, que entrou em vigor no dia $1 .^{\circ}$ de fevereiro de 2008, assinado por 37 países. Esse fato favorece o tráfico internacional na Amazônia. 


\section{Referências}

HAZEU, Marcel (org.). Tráfico de mulheres, crianças e adolescentes para fins de exploração sexual na Amazônia. Belém: Txai/OIT/Emaus, 2003;159p.

HAZEU, Marcel; FIGUEIREDO, Danielle Lima de. Migração e tráfico de seres bumanos para Suriname \& Holanda. Belém: Txai/Emaús, 2006.

LEONEL, Mauro. Bio-sociodiversidade: preservação e mercado.Revista Estudos Avançados, São Paulo. 2000, v. 14, n. 38.

LOUREIRO, Antônio J. S. Amazônia 10.000 anos. Manaus: Metro Cúbico, 1982.

MOREIRA JR. José Vicente. Tráfico Internacional de Mulheres e Crianças. Disponível em: < http://www.midiaindependente.org/pt/blue/2005/05/316578.shtml>.

OLIVEIRA, R. S. de. Um olhar sobre as redes de prostituição e tráfico de mulheres na fronteira Brasil-Venezuela a partir das rodovias BR-174 e Troncal 10. In: DIEZ AÑOS DE CAMBIOS EN EL MUNDO, EN LA GEOGRAFÍA Y EN LAS CIENCIAS SOCIALES, 1999-2008. ACTAS DEL X COLOQUIO INTERNACIONAL DE GEOCRÍTICA, Universidad de Barcelona, 26-30 de mayo de 2008. Disponível em: < http://www.ub.es/geocrit/-xcol/222.htm>.

TORRES, Iraildes Caldas. As novas amazônidas. Manaus: Editora da Universidade Federal do Amazonas, 2005.

86 Somanlu, ano 9, n. 1, jan./jun. 2009 